\title{
The validity and reliability of Kişilerarası Çekicilik Ölçeği: the Interpersonal Attractiveness Scale Geçerlik güvenirlik çalışması
}

\author{
Erkan Yaman $^{1}$
}

\begin{abstract}
The aim of this research is to develop the Interpersonal Attractiveness Scale and examine its validity and reliability. The sample of the study consisted of 1145 students from Sakarya University. In this study, construct validity, internal consistency, test-retest reliability, and item analysis of the scale were examined. As a result of factor analysis for construct validity, four factors have emerged which are named physical appearance, personal characteristics, the frequency of visual, and values. These subscales consist of 19 items and account for the $46 \%$ of the total variance. The internal consistency reliability coefficients were .77 for physical appearance, .74 for personal characteristics, .81 for the frequency of visual, and .74 for values. Findings also demonstrated that item-total correlations ranged from .40 to .72 . Test-retest reliability coefficients were .38 and .60 for four subscales, respectively. The item-total correlations ranged from .40 to .72. According to these findings the Interpersonal Attractiveness Scale can be regarded as a valid and reliable instrument that could be used in the field of psychology.
\end{abstract}

Keywords: Interpersonal attractiveness, validity, reliability

(Extended English abstract is at the end of this document)

\section{Özet}

$\mathrm{Bu}$ araştırmanın amacı Kişilerarası Çekicilik Ölçeğini geliştirmek ve geçerlik, güvenirlik analizlerini yapmaktır. Araştırmanın örneklemini, Sakarya Üniversitesinde öğrenim gören 1145 üniversite öğrencisi oluşturmaktadır. Yapılan faktör analizi sonucunda toplam varyansın \% 46'sını aç1klayan, on dokuz madde ve dört alt boyuttan oluşan bir ölçme aracı elde edilmiştir. $\mathrm{Bu}$ alt boyutlar sirasiyla fiziksel görünüm, kişisel özellikler, görme sıkllğ1 ve değerlerdir. Ölçeğin faktör yükleri .59 ile .74 arasında değişmektedir. İç tutarlık güvenirlik katsayıları fiziksel görünüm için .77, kişisel özellikler için .74, görme siklı̆̆1 için .81 ve değerler için .74 olarak hesaplanmıştır. Ölçeğin güvenirlik kat saylları ise fiziksel görünüm için .38 , kişisel özellikler için .42, görme sılklğı için .60 ve değerler için .53 olarak bulunmuştur. Madde analizi sonucunda alt ölçeklerin madde toplam puan korelasyonlarının .40 ile $\quad .72$ arasında değisstiği görülmüştür. $\mathrm{Bu}$ bulgulara dayanarak Kişilerarası Çekicilik Ölçeği'nin psikolojik araştırmalarda kullanılabilecek, geçerli ve güvenilir bir ölçme aracı olduğu söylenebilir.

Anahtar Kelimeler: Kişilerarası çekicilik, geçerlik, güvenirlik.

\footnotetext{
${ }^{1}$ Associate Professor, Sakarya Univesity, Faculty of Education, eyaman@sakarya.edu.tr
} 


\section{Giriş}

Kişilerarası ilişkiler kavramı, 1950’li yıllardan bu yana sosyal psikolojinin önemli konularından biri haline gelmiştir. Sosyal psikoloji, çeşitli sorunların yanı sıra, insanların dostlarında veya yakınlarında neyi aradıklarını, mahrem ilişkileri sürdürmenin niçin güç olduğunu araşurmaktadır. Bu ve benzeri sorunlar kişilerarası çekim konusuyla ilgilidir (Bilgin, 2000). Çekicilik, bir kişinin bir başkasından hoşlanmasını sağlayan şeydir. Bir insanın çekimine (albenisine, cazibesine) girildiğinde o kişiyi tanımak ve onunla biraz zaman geçirmek istenilir. Arkadaşlıkların başlaması için çekicilik şarttır (Hogg ve Vaughan, 2007). Sosyal psikologlar çekiciliği daha çok bilişsel denge ve öğrenme kuramlarıyla açıklamaktadır. Örneğin bilişsel denge kuramı, kişilerin dengeli ilişkiler yasayabileceği kişiler tarafindan çekilme eğiliminde olduğunu, kişilerin kendisi gibi düşünen ve davranan kişileri daha çekici bulduğunu öne sürer (Cüceloglu, 1998).

Kişilerarası çekicilik ise bir insana karşı olumlu ya da olumsuz tutum olarak tanımlanabilir (Berscheid ve Walster, 1978). 1970'li yıllara kadar sosyal psikolojide kişilerarası çekicilik adı altında yürütülen çalışmalar, birden çok kuramsal çerçeve altında yürütülmüş ve bazı genel-geçer saptamalar ortaya konmuştur. Örneğin, fiziksel yakınlık, tutum, inanç, yaş, sosyal düzey, coğrafi bölge, eğitim, boy, güzellik-yakışıklılık gibi boyutlardaki bir takım benzerlikler insan ilişkilerini olumlu yönde etkilediği bulgulanmıştır (Hortaçsu, 2003). Kişilerarası çekicilik ile ilgili yapılan çalışmalar genellikle insanları birbirine çeken dört temel faktör üzerinde birleşirler. Bunlar; fiziksel çekicilik, fizikî yakınlık benzerlik ve aşinalıktur.

Fiziksel çekicilik, sevgi ya da çekiciliği etkileyen güçlü bir faktördür (Freedman, Sears, \& Carlsmith, 1993). Nitekim yapılan araştırmalar fiziksel güzelliğin, özellikle güzel bir yüzün, birçok olumlu beklentiyi de beraberinde getirdiğindi göstermektedir (Kağıtçıbaşı, 2004).

Diğer yandan coğrafi mesafe küçüldükçe, çekime dayalı ilişkiler artma eğilimi gösterir (Bilgin, 2000). Bir kişinin bir başka kişiye fiziksel yakınlığı, aradaki çekiciliği kolaylaştıran bir etkendir. Örneğin Festinger, Schachter ve Back (1950), insanların; oturdukları binanın diğer katlarında ya da başka binalarda oturanlardan daha çok kendi katlarında oturanları arkadaş olarak seçtiklerini bulgulamıştır (akt, Sprecher, 1998). Yakında oturan insanlar kendilerine kolay erişilebilecek insanlardır. Onlarla kurulacak etkileşim çok az çaba gerektirir, bu etkileşimin bedeli küçük fakat ödülü büyüktür (Hogg ve Vaughan, 2007).

Benzerlik, kanaatlerin, zevklerin, nefretlerin, bağlanma biçimlerinin, enerji düzeylerinin ve boyutların benzerliği ya da paylaşılmasıdır. Benzerlik olmadığı takdirde ilişkinin devamı güçtür. Tutum ve değerlerin benzerliği çekiciliğin en önemli belirleyicilerindendir (Bilgin, 2000; Sprecher, 1998). 
İnsanlar genellikle kendileri gibi düşünen kişilerden oluşan bir çevre içinde bulunmaktan hoşlanmaktadırlar. İnsanlar için nesnelerin birbiri ile uyumlu, mantıklı, tutarlı olması kadar, kendi inanç, düşünce, davranış, duygu ve tutumlarının da tutarlı olması yönünde güçlü eğilimleri bulunmaktadır (Kağıtıbaşı, 2004). Kişilerarası çekicilikte benzerlik iki açıdan incelenebilir. Birincisi kişiler, kendilerine benzer insanlardan hoşlanırlar. İkincisi, kişiler hoşlandıkları insanlara var olduğundan daha fazla benzediklerini düşünürler (Bercheid ve Walster, 1978). Kişiler, kendi düşünce, duygu ve davranışlarına benzeyen; kendi bedensel güzellikleri kadar güzelliğe sahip olan; aynı grup ya da sosyal çevrede kendileriyle aynı statüyü paylaşan; hemen hemen kendileriyle aynı yaşta olan kişileri çekici bulurlar (Cüceloğlu, 1998).

Tıpkı diğer duyuşsal özellikler gibi kişilerarası çekiciliğin de doğrudan ölçülmesi ve değerlendirilmesi oldukça zordur. Fakat davranışa dönüştürülebilen bu özelliklerin gözlenmesi ya da geçerli ve güvenilir ölçme araçlarının kullanılması gerekebilir. Öte yandan duyuşsal özellikler ciddi ölçüde kültürün izlerini taşır ve büyüdüğü kültürün özelliklerine göre şekillenir. Bu bağlamda bu çalışmanın amacı kişilerarası çekiciliği ölçmeye yarayan bir kişilerarası çekicilik ölçeği geliştirmektir.

\section{Yöntem}

\section{Çalışma Grubu}

Bu çalışma Sakarya üniversitesinde öğrenim gören 1145 öğrenci üzerinde yürütülmüştür. Katılımciların 694 (\% 60.6) bayan, 450 (\% 39.3)'si erkektir. 18 ile 23 yaş arasında olan katılımcıların yaş ortalaması ise 21.56 ' dır. Ayrıca test tekrar test güvenirlik çalışması için Sakarya üniversitesinde öğrenim gören 115 Eğitim Fakültesi öğrencisine ölçek üç hafta arayla tekrar uygulanmıştır.

\section{İşlem}

Ölçek maddelerinin hą̦rlanması. Bu süreçte öncelikle kişilerarası çekicilik alanında yapılan araştırmalar ve kişilerarası çekicilikle ilgili elde edilen kuramsal bilgiler incelenmiştir. Aynı zamanda kişilerarası çekiciliği değerlendirmeye yönelik yurtiçi ve yurtdışında geliştirilen ölçme araçlarının faktör yapıları ve ölçek maddeleri de incelenmiş ve 45 maddelik bir madde havuzu oluşturulmuştur.

Bir sonraki aşamada 45 madde psikoloji, psikolojik danışmanlık ve rehberlik, eğitim yönetimi, Türkçe, ölçme ve değerlendirme alanlarında uzman olan altı öğretim üyesine inceletilmiş ve anlaşılabilillik, ifadelendirme, kişilerarası çekicilik yapısının ne düzeyde ölçebildiği açısından beşli bir derecelendirme üzerinden değerlendirmeleri istenmiştir. Bu uygulamada öğretim üyeleri her bir maddeyi üç gösterge açısından değerlendirmiş ve bu değerlendirmeler sonucunda yedi madde ölçekten çıkarılmıştır. Ölçekte yer alan maddelerle ilgili katılma düzeyini ifade etmek için beşli Likert tipi dereceleme kullanılmıştır. $\mathrm{Bu}$ dereceleme, "Kesinlikle katıllyorum (5), Katıllyorum (4), Kararsızım (3), Katılmıyorum (2) ve Kesinlikle katılmıorum (1)” şeklinde oluşturulmuş ve bu maddeler üzerinde geçerlik ve güvenirlik analizleri yapılmıştır. 
Geçerlik ve güvenirlike çalşsmalar. Kişilerarası Çekicilik Ölçeği'nin (KÇÖ) 45 maddelik deneme formundan elde edilen verilerin yapı geçerliği için açımlayıcı ve doğrulayıcı faktör analizleri yapılmıştır. Açımlayıcı faktör analizi (AFA) bir ölçekteki maddelerin birbirini dışta tutan, daha az sayıda faktöre ayrılıp ayrılmadığını ortaya çıkarmak için yapılmaktadır. Aynı faktör grubunda toplanan maddelere, maddelerin içeriğine göre bir ad verilmeye çalışllır (Balc1, 2009). Faktör yüklerinin yüksek olması, değişkenin söz konusu faktör altında yer alabileceğinin bir göstergesi olarak görülür. Açıklanan varyans oranının tek faktörlü yapılarda \%30 çok faktörlü ise \% 40’1n üzerinde olması, davranış bilimlerinde yapılan test geliştirme çalışmalarında yeterli görülmektedir (Büyüköztürk, 2004).

Doğrulayıcı faktör analizi (DFA) ise kuramsal bir temele dayanarak çeşitli değişkenlerden oluşturulan faktörlerin gerçek verilerle ne derece uyum gösterdiğini değerlendirmeye yönelik bir analizdir. DFA'da sınanan modelin yeterliğinin belirlenmesi için çok sayıda uyum indeksi kullanılmaktadır (Büyüköztürk, Akgün, Kahveci ve Demirel, 2004).

Bu çalışmada yapılan DFA için çoklu uyum indeksleri kullanılmış ve Ki-Kare Uyum Testi (Chi-Square Goodness), iyilik uyum indeksi (goodness of fit index, GFI), karşılaştırmalı uyum indeksi (comparative fit index, CFI), normlaştırılmış uyum indeksi (normed fit index, NFI), göreli uyum indeksi (relative fit index, RFI), fazlalık uyum indeksi (incremental fit index, IFI), ortalama hataların karekökü (root mean square residuals, RMR) ve yaklaşık hataların ortalama karekökü (root mean square error of approximation, RMSEA) uyum indeksleri incelenmiştir.

Bu uyum indekslerinde alanyazında olduğu gibi GFI, CFI, NFI, RFI ve IFI >.90, RMSEA ve SRMR<.05 ölçüt olarak alınmıştır (Hu ve Bentler, 1999). KÇÖ’nin güvenirlik çalışmaları olarak iç tutarlık ve test tekrar test güvenirlik kat saylları incelenmiştir. Madde analizi için ise düzeltilmiş madde toplam puan korelasyonları hesaplanmıştır. Ölçeğin geçerlik ve güvenirlik analizleri için SPSS 11.5 ve LISREL 8.54 programları kullanılmıştır.

\section{Bulgular}

\section{Yapı Geçerliği-Açımlayıcı Faktör Analizi}

Kişilerarası Çekicilik Ölçeği’nin yapı geçerliğini incelemek için yapılan açımlayıcı faktör analizinde öncelikle bütün maddeler arasındaki korelasyon matrisi incelenmiş, maddeler arasında anlamlı ilişkilerin olup olmadığına bakılmış ve faktör analizinin yapılabilmesine uygunluk gösterir nitelikte anlamlı ilişkilerin olduğu görülmüştür. Faktörleri belirlemek amacıyla Temel Bileşenler Analizi Yöntemi kullanılmıştır. Temel Bileşenler Analizi’nden önce verilerin faktörlenebilirliği Barlett Sphericity ve KMO Örneklem Yeterliği testleri ile incelenmiştir.

Verilerin faktör analizine uygunluğu için KMO .60'dan yüksek ve Barlett testinin anlamlı çıkması gerekmektedir (Büyüköztürk, 2004). Bu çalışmada KMO örneklem uygunluk katsayısı .811 ve 
Yaman, E. (2015). Kişilerarası Çekicilik Ölçeği: Geçerlik güvenirlik çalışması. International Journal of Human Sciences, 12(1), 1547-1557. doi: $10.14687 /$ ijhs.v12i1.3139

Barlett Sphericity testi $\chi^{2}$ değeri 3,983 (p<.000) anlamlı bulunmuştur. Bu değerler verilerin faktör analizi için uygun olduğunu göstermektedir.

Kişilerarası Çekicilik Ölçeği için yapılan açımlayıcı faktör analizinde temel bileşenler tekniği kullanılmıştır. Kişilerarası Çekicilik Ölçeği’nin faktör yapısını incelemek amacıyla öncelikle 38 madde serbest bırakılarak döndürülmüss ve ölçek maddelerinin on faktör altında toplandığ1 görülmüştür. Ancak ölçek geliştirme sürecinde dört faktör elde edilmek istendiği için temel bileşenler tekniği dört faktörle sınırlandırılmıştır. Faktörlerin kendileriyle yüksek ilisski veren maddeleri bulmaları ve kolayca yorumlanabilmeleri amacyyla eksen döndürmesi (rotation) yapılmıştır. Eksen döndürmesi sırasında varimax tekniğinden yararlanılmıştır. Yapılan analiz sonucunda toplam varyansın \%46'sını açılklayan, 19 madde ve 4 alt ölçekten oluşan bir ölçme aracı elde edilmiştir. Her bir faktöre ait maddelerin faktör yükleri sonuçları Tablo 1'de sunulmuştur.

\section{Tablo 1-Kişilerarası Çekicilik Ölçeği faktör analizi bilgileri}

\begin{tabular}{|c|c|c|c|c|}
\hline Madde No & Fiziksel Görünüm & Kişisel Özellikler & Görme S1klı̆̆1 & Değerler \\
\hline Madde 9 & .70 & & & \\
\hline Madde17 & .74 & & & \\
\hline Madde 23 & .62 & & & \\
\hline Madde 27 & .64 & & & \\
\hline Madde 29 & .59 & & & \\
\hline Madde 10 & & .50 & & \\
\hline Madde 12 & & .58 & & \\
\hline Madde 13 & & .59 & & \\
\hline Madde 20 & & .53 & & \\
\hline Madde 21 & & .53 & & \\
\hline Madde 30 & & .52 & & \\
\hline Madde 31 & & .61 & & \\
\hline Madde 35 & & .60 & & \\
\hline Madde 14 & & & .81 & \\
\hline Madde 15 & & & .77 & \\
\hline Madde 19 & & & .59 & \\
\hline Madde 33 & & & & .71 \\
\hline Madde 36 & & . & & .64 \\
\hline Madde 38 & & & & .37 \\
\hline $\begin{array}{c}\text { Açıklanan varyans } \\
\% 46\end{array}$ & $\% 14.34$ & $\% 13.89$ & $\% 9.88$ & $\% 7.87$ \\
\hline
\end{tabular}

AFA sonucunda elde edilen faktörlerin isimlendirilmesinde kuramsal yapıya uygunluk ve faktörleri oluşturan maddelerin içeriği dikkate alınmıştır. AFA sonucunda elde edilen alt ölçeklerden birincisi firikesel görünüm olarak adlandırılmıştır. Bu boyut kişilerarası çekicilikte fiziksel görünümü vurgulayan maddeler içermektedir. Beş maddeden oluşan bu alt ölçek toplam varyansın \%14.34'ünü açıklamakta ve faktör yükleri .59 ile .74 arasında değişmektedir. Bu alt ölçekte yer alan maddelere örnek olarak "Fiziksel görünüş benim için önemlidir” gösterilebilir. İkinci alt ölçek kişisel özellikler 
olarak adlandırılmıştır. Sekiz maddeden oluşan ve faktör yükleri .50 ve .60 arasında sıralanan bu alt ölçek toplam varyansın \%13.89’unu açıklamaktadır. Bu alt ölçek kişilerarası çekicilikte kişisel özellikleri ön plana çıkaran sorular içermektedir. "Sıcakkanlı insanları çekici bulurum.” maddesi bu alt ölçeğe örnek olarak gösterilebilir. Üçüncü alt ölçek görme sıklĭğdır. Faktör yükleri .59 ile .81 arasında sıralanan ve toplam varyansın \%9.88'ini açıklayan bu alt ölçek üç maddeden oluşmaktadır. Görme sıklı̆̆1 alt ölçeğinde yer alan maddelere örnek olarak “Aynı ortamı paylaştı̆ı̆m bir insanı daha çekici bulurum.” maddesi gösterilebilir. Dördüncü ve son alt ölçek olan değerler olarak isimlendirilmiştir. $\mathrm{Bu}$ alt ölçek kişilerarası ilişkilerde değerlerin önemine vurgu yapmaktadır. Üç maddeden oluşan değerler alt ölçeğine ilişkin maddelerin faktör yükleri .37 ile .71 arasında değişmekte ve bu alt ölçek toplam varyansın \%7.87’sini açıklamaktadır. Bu alt ölçekte yer alan maddelere örnek olarak “Önyargılar çekiciliği örseler.” maddesi gösterilebilir. Kişilerarası İlişkiler alt ölçekleri arasındaki korelasyona ilişkin bulgular Tablo 2'de verilmiştir.

Tablo 2- Kişilerarası Çekicilik Ölçeği faktörler arası korelasyon katsayıları

\begin{tabular}{lcccc}
\hline Faktör & Fiziksel Görünüm & Kişisel Özellikler & Görme S1klı̆̆1 & Değerler \\
\hline Fiziksel Görünüm & - & & & \\
Kişisel Özellikler & $.34^{* *}$ & - & & \\
Görme Sıklı̆̆1 & $.23^{* *}$ & $.25^{* *}$ & - & \\
Değerler & $.23^{* *}$ & $.31^{* *}$ & $.20^{* *}$ & - \\
$* * \mathrm{p}<.01$ & & & & \\
\hline
\end{tabular}

\section{Yapı Geçerliği-Doğrulayıcı Faktör Analizi}

Ölçekte bulunan faktörlerin kuramsal olarak oluşturulan model açısından doğrulanması amacıyla DFA uygulanmıştır. Yapılan analiz sonucunda, ölçeğin kuramsal olarak oluşturulan modelde öngörüldüğü gibi dört alt boyutta uyum verdiği ve ki-kare değerinin $\left(x_{2}=908.68\right.$, sd=146, $\mathrm{p}=0.00$ ) anlamlı olduğu görülmüştür. Uyum indeksi değerleri ise RMSEA=.068, NFI=.88, CFI=.90, $\mathrm{IFI}=.90, \mathrm{RFI}=.96, \mathrm{GFI}=.92$ ve $\mathrm{AGFI}=.90$ olarak bulunmuştur. Bu uyum indeksi değerleri dört boyutlu modelin uyumlu olduğunu (Hu \& Bentler, 1999) göstermektedir. 


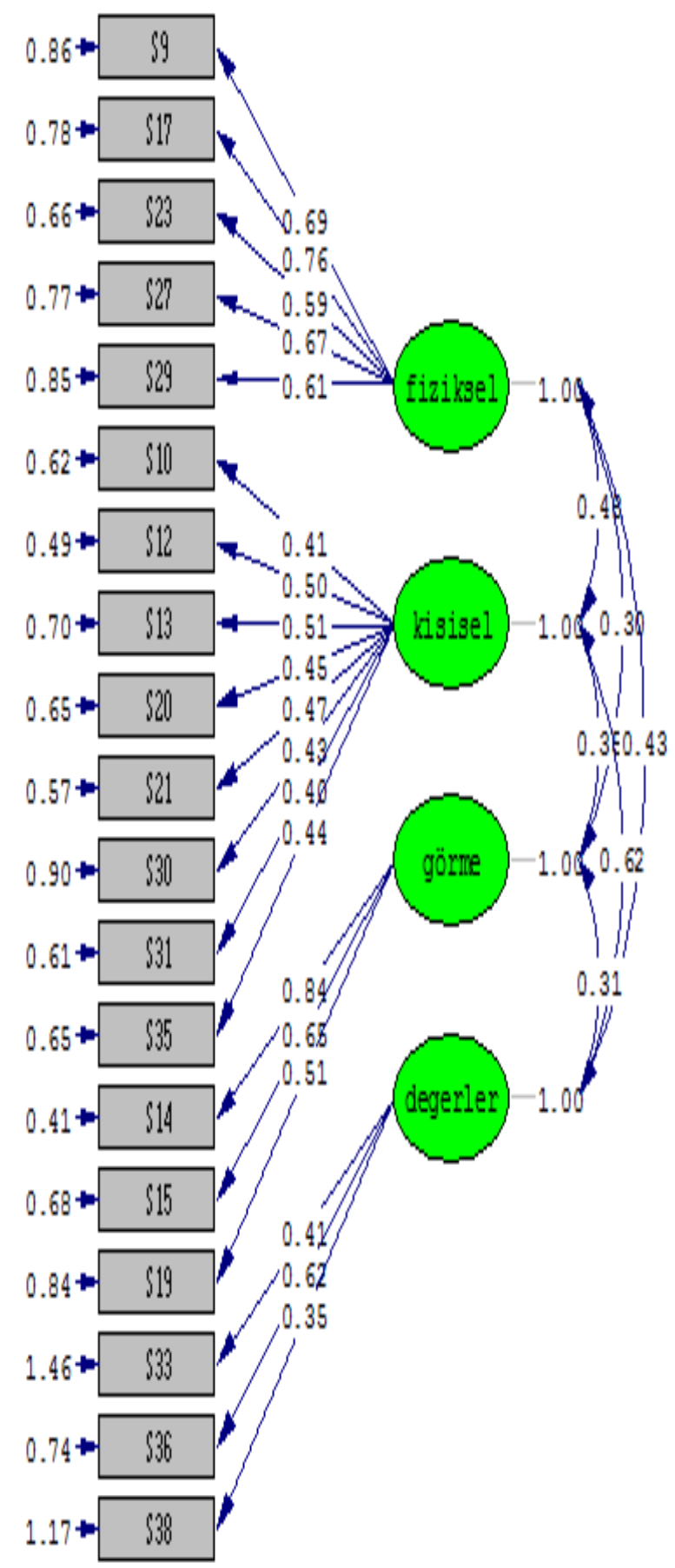

Chi-Square $=908.68$, df $=146, \mathrm{p}-\mathrm{value}=0.00000, \mathrm{RMSEA}=0.068$

Şekil 1: DFA analizi Path diyagramı 
Yaman, E. (2015). Kişilerarası Çekicilik Ölçeği: Geçerlik güvenirlik çalışması. International Journal of Human Sciences, 12(1), 1547-1557. doi: 10.14687/ijhs.v12i1.3139

\section{Madde Analizi}

Kişilerarası Çekicilik Ölçeği madde analizi için ölçekte yer alan maddelerin madde-toplam korelasyonları hesaplanmıştır. Düzeltilmiş madde toplam korelasyonlarının hesaplanmasında her boyutun kendi toplam puanı kullanılmıştır. Düzeltilmiş madde-toplam korelasyonları fiziksel görünüm alt boyutu için .57 ile .66, kişisel özellikler alt boyutu için .46 ile .55 , görme sıklı̆̆1 alt boyutu için .58 ile .72, değerler alt boyutu için .40 ile .52 arasında değerler almıştır. Düzeltilmiş madde-toplam korelasyonlarına ( $\mathrm{r}_{\mathrm{j} \mathrm{x})}$ ait bulgular Tablo 3'de gösterilmiştir.

Tablo 3- Kişilerarası Çekicilik Ölçeği Düzeltilmiş Madde Toplam Puan Korelasyonları

\begin{tabular}{ccccc}
\hline Madde No & Fiziksel Görünüm & Kişisel Özellikler & Görme S1kliğ1 & Değerler \\
\hline Madde 9 & $\mathrm{r}_{\mathrm{ix}}$ & $\mathrm{r}_{\mathrm{ix}}$ & & \\
Madde17 & .63 & & & \\
Madde 23 & .66 & & & \\
Madde 27 & .59 & & & \\
Madde 29 & .60 & & & \\
\hline Madde 10 & .57 & & & \\
Madde 12 & & .56 & & \\
Madde 13 & & .55 & & \\
Madde 20 & & .49 & & \\
Madde 21 & & .51 & & \\
Madde 30 & & .52 & & \\
Madde 31 & & .46 & & \\
Madde 35 & & .50 & & \\
\hline Madde 14 & & & & \\
Madde 15 & & & & \\
Madde 19 & & & & \\
\hline Madde 33 & & & & \\
Madde 36 & & & & \\
Madde 38 & & & & \\
\hline
\end{tabular}

\section{Güvenirlik}

Kişilerarası Çekicilik Ölçeğinin güvenirlik çalışmaları olarak iç tutarlık ve test-tekrar test güvenirlikleri incelenmiştir. Yapılan analiz sonucunda iç tutarlık fiziksel görünüm alt ölçeği için .77, kişisel özellikler için .74, görme sıklığ1 alt ölçeği için .81, değerler alt ölçeği için .74 ve ölçeğin bütünü için .83 olarak bulunmuştur. Test-tekrar güvenirlik çalışması için Kişilerarası Çekicilik Ölçeği Sakarya Üniversitesi Eğitim Fakültesi’nin çeşitli bölümlerinde öğrenim gören 115 üniversite öğrencisine 3 hafta arayla iki kez uygulanmıştır. Ölçeğin test-tekrar test güvenirliği fiziksel görünüm alt boyutu için .38, kişisel özellikler alt boyutu için .42, görme sıklığı alt boyutu için . 60, değerler alt boyutu için .53 ve ölçeğin bütünü için .72 olarak bulunmuştur. Tablo 4’te Kişilerarası Çekicilik Ölçeğinin iç tutarlık ve test-tekrar test güvenirlik katsayıları verilmiştir. 
Tablo 5- Kişilerarası Çekicilik Ölçeği test-tekrar test ve iç tutarlık yöntemiyle hesaplanan güvenirlik katsayıları

\begin{tabular}{lcc}
\hline Faktör & Test-tekrar test & İç tutarlık \\
\hline Fiziksel Görünüm & .38 & .77 \\
Kişisel Özellikler & .42 & .74 \\
Görme S1klığı & .60 & .81 \\
Değerler & .53 & .74 \\
\hline
\end{tabular}

\section{Ölçeğin Puanlanması}

Kişilerarası Çekicilik Ölçeği’ndeki toplam madde sayısı 19'dur. Ölçek 5'li likert tipi olduğu için ölçekten alınabilecek en düşük puan 19, en yüksek puan 95'tir. Ölçekte ters madde bulunmamaktadır. İlgili alt boyuttan alınan puan yükseldikçe bireylerin kişilerarası çekicilikte o alt ölçeğe ait özellikleri önemseme derecesi artmaktadır.

\section{Tartı̧̧ma}

$\mathrm{Bu}$ araştırmanın amacı kişilerarası çekiciliği belirlemeye dönük bir ölçek geliştirmek ve geçerlik ve güvenirlik analizlerini gerçekleştirmektir. Araştırmanın örneklemi ölçek geliştirme çalışmaları için öngörülen sayı bakımından yeterli niteliktedir. Aynı zamanda araştırmadan elde edilen bulgular Kişilerarası Çekicilik Ölçeği’nin yüksek düzeyde geçerlik ve güvenirlik ölçülerine sahip olduğunu kanıtlamıştır (Tabachnick, \& Fidell, 1996). Bu çalışmada ölçeğin faktör yapısını belirlemek amacıyla açımlayıcı faktör ve doğrulayıcı faktör analizleri yapılmış; ölçek maddelerinin dört boyutta toplandığ1 görülmüştür. Daha sonra bu boyutlarda toplanan maddeler incelenmiş ve değerlendirdikleri özellikler bakımından bu boyutlar; fiziksel görünüm, kişisel özellikler, görme sıklığı ve değerler şeklinde adlandırılmıştır.

Ölçekte yer alan on dokuz maddenin tümünün kendi boyutlarında .30 faktör yükü ölçütünden yüksek, diğer boyutlarda ise düşük olması faktörlerin bağımsızlığını göstermesi açısından son derece önemlidir. Madde analizi sonucunda ölçeğin düzeltilmiş madde toplam puan korelasyonlarının .54 ile .78 arasında sıralandığı görülmüştür. Madde toplam puan korelasyonunun yorumlanmasında .30 ve daha yüksek olan maddelerin bireyleri ölçülen özellik bakımından iyi derecede ayırt ettiği dikkate alındığında (Büyüköztürk, 2004), bu kat sayıların yeterli olduğu ifade edilebilir. Ölçeğin iç tutarlık güvenirlik kat sayıları psikoloji ve eğitim alanında kullanılan ölçekler için gerekli olan 70 (Tezbaşaran, 1996) ölçütünün üzerinde bulunmuştur. Bu kat sayılar ölçekte yer alan maddelerin birbirleri ile tutarlı, dolayısıyla iç tutarlık anlamındaki güvenirliğin yüksek olduğunu kanıtlamaktadır. Üç hafta arayla yapılan test tekrar test güvenirlik çalışmasında ise iki uygulama arasındaki korelasyonların oldukça yüksek olduğu görülmüştür. Bu sonuç, ölçeğin kararlılıkla aynı yapıyı ölçtüğünü ortaya koymaktadır. 
Kişilerarası Çekicilik Ölçeği’nin psikometrik özelliklerinin incelendiği bu çalışmadan elde edilen tüm bulgular geliştirilen ölçeğin kişilerarası çekicilik düzeylerini saptamada geçerli ve güvenilir bir araç olarak kullanılabileceğini göstermektedir.

Ancak Kişilerarası Çekicilik Ölçeği’nin kullanılacağı araştırmaların yapılması bu ölçeğin ölçme gücüne önemli katkılar sağlayacaktır.

\section{Kaynakça}

Balc1, A. (2009). Sosyal bilimlerde araştırma: Yöntem, teknik ve ilkeler. Ankara: PegemA Yayınevi.

Berscheid, E. \& Walster, E.H. (1978). Interpersonal attraction, New York: Addison-Wesley.

Bilgin, N. (2000). Sosyal psikolojizye giriș, İzmir: Ege Üniversitesi Edebiyat Fakültesi Yayınları.

Büyüköztürk, Ş. (2004). Veri analiz̧ el kitabı. Ankara: Pegem Yayıncılık.

Büyüköztürk, Ș., Akgün, Ö., Kahveci, Ö. \& Demirel, F. (2004). Güdülenme ve Öğrenme Stratejileri Ölçeğinin Türkçe formunun geçerlik ve güvenirlik çalışması. Kuram ve Uygulamada Eğitim Bilimleri, 4(2), 207-239.

Cüceloğlu, D. (1998). İnsan ve davranışı, İstanbul: Remzi Kitapevi.

Finkel, E. J., \& Eastwick, P. E. (2015). Interpersonal Attraction: In Search of a Theoretical Rosetta Stone. In J. A. Simpson \& J. F. Dovidio (Eds.), APA Handbook of personality and social psychology, volume 3: Interpersonal relations (pp. 179-210). Washington: American Psychological Association.

Freedman, J.L.; Sears, D.O. \& Carlsmith, J.M. (1993). Sosyal psikoloji, A. Dönmez (çev.), Ankara: İmge Yayınevi.

Hogg, M.A. \& Vaughan, G.M. (2007). Sosyal psikoloji, İ. Yıldız\& A. Gelmez (çev.), Ankara: Ütopya Yayınevi.

Hortaçsu, N. (2003). İnsan ilişkileri. Ankara: İmge Yayınları.

Hu, L.T., \& Bentler, P.M. (1999). Cutoff criteria for fit indexes in covariance structural analysis: Conventional criteria versus new alternatives. Structural Equation Modeling, 6, 1-55.

Kağıtçıbaşı, Ç. (2004). Yeni insan ve insanlar, İstanbul: Evrim Yayınları.

Myers, G.D. (1993). Social psychology, New York: McGraw-Hill.

Sprecher, S. (1998). Insiders' perspectives on reasons for attraction to a close other, Social Psychology Quarterly, 61, 287-300.

Tabachnick, B.G., \& Fidell, L.S. (1996). Using multivariate statistics. New York, NY: Harper Collins College Publishers.

Tezbaşaran, A. (1996). Likert tipi ölgek geliștirme kılavuzu. Ankara: Türk Psikologlar Derneği Yayınları.

\section{Extended English Abstract}

Research on interpersonal attraction has a checkered history. It flourished in the 1960s and 1970s before being largely eclipsed by research on established romantic relationships in the 1980s. As the 1990s approached, it reemerged in a barely recognizable form as a major prong of evolutionary 
psychology, which largely jettisoned the most central research questions from previous decades. Then, in the first decade of the 21 st century, broad interest in interpersonal attraction reemerged, inspired in part by the power afforded by major dating innovations in the business world, including online dating and speed-dating. This reemergence not only built upon the flourishing literature deriving predictions from evolutionary principles, but it also revitalized topics that had been largely neglected for decades (Finkel \& Eastwick, 2015).

\section{Method}

The sample of the study consisted of 1145 students who are studying in Sakarya University. Of the participants, 694 were females; 450 were males. The mean age of the participants was 21.56.

As a first step of the procedure, relevant literature and studies of interpersonal attractiveness were examined. Relevant literature has been reviewed in order to identify the behaviors that can be listed under the banner of interpersonal attractiveness.

Following the identification of interpersonal attractiveness, a pre-form was developed, consisting of 45 items. The items of the pre-form were evaluated in terms of content validity by academicians and measurement experts. After the corrections and eliminations, 38 items were retained for the scale. In this study, exploratory and confirmatory factor analyses were performed to examine the factor structure of the scale according to the data obtained from the Turkish participants. To understand whether a model is consistent with the data, the Goodness-of-Fit Index (GFI) and the Comparative-Fit Index (CFI) should be above .90. In addition, the Standardized Root Mean Square Residual (RMSEA) should be. 05 or below to indicate a satisfactory fit. In addition to these, whether or not items have significant factor loadings and regardless of factor correlations and item errors display significant relationships have also been examined (Hu, \& Bentler, 1999). Test re-test and internal consistency reliability analyses and item analysis of the inventory were examined.

\section{Results}

As a result of factor analysis for construct validity, four factors have emerged which are named as physical appearance, personal characteristics, the frequency of visual, and values. These factors consist of 19 items and account for the $46 \%$ of the total variance. Factor loadings ranged from .52 to .78 for physical appearance, .54 to .76 for personal characteristics, .71 to .85 for the frequency of visual, and .52 to .75 values. Similarly, the results of CFA indicated that the model was well fit and Chi-Square value $(\mathrm{x} 2=914.29, \mathrm{~N}=515, \mathrm{sd}=220, \mathrm{p}=0.00)$ which was calculated for the adaptation of the model was found to be significant. The goodness of fit index values of the model were RMSEA $=.078, \mathrm{NFI}=.95, \mathrm{CFI}=.96, \mathrm{IFI}=.96, \mathrm{RFI}=.94$, and $\mathrm{SRMR}=.074$. The internal consistency reliability coefficients were .77 for physical appearance, .74 for personal characteristics, .81 for the frequency of visual, and .74 for values. Findings also demonstrated that item-total correlations ranged from .40 to .72 . Test-retest reliability coeff icients were .38 and .60 for four subscales, respectively. The item-total correlations ranged from .40 to .72 . Test-retest reliability coeff icients were .38 and .60 for four subscales, respectively.

\section{Conclusion and Recommendations}

The aim of this research was develop the IAS and examine its psychometric properties. Overall, findings demonstrated that this scale had acceptable and high validity and reliability scores (Büyüköztürk, 2004; Büyüköztürk, Akgün, Özkahveci \& Demirel, 2004; Tabachnick, \& Fidell, 1996; Tezbaşaran, 1996). Therefore, the scale is concluded to be a valid and r0065liable instrument that can be used in the field of education.

However, because participants were public employees in the current study, the examination of factor structure of the IAS for other populations should be studied in future. 